Fifth International Conference on Sustainable Construction Materials and

Technologies. http://www.claisse.info/Proceedings.htm

\title{
SULFATE RESISTANCE OF SUSTAINABLE GEOPOLYMER MORTARS
}

\author{
Yurdakul Aygörmez ${ }^{1, *}$, Orhan Canpolat ${ }^{1}$, Mukhallad M AI- \\ Mashhadani', Mucteba Uysal ${ }^{2}$, and Furkan Şahin ${ }^{2}$
}

${ }^{I}$ Yildiz Technical University, Department of Civil Engineering, 34220, Istanbul, Turkey, E-mail: <aygormez@yildiz.edu.tr>, <canpolat@yildiz.edu.tr>, $<$ mukhallad.mohammad@std.yildiz.edu.tr>

${ }^{2}$ Istanbul University-Cerrahpasa, Department of Civil Engineering, 34320, Istanbul, Turkey, E-mail: 〈mucteba.uysal@istanbul.edu.tr>, 〈furkansahintr@gmail.com>,

\begin{abstract}
Nowadays, besides the important properties such as strength, durability and costs for construction materials, criterion such as environmental and sustainability have gained importance. For this reason, projects related to the production of cementless concrete especially in the academic field are being carried out. These well-meaning works take place in the media and create an expectation. In the concept of cementless concrete, Portland cement is generally replaced by geopolymers. Geopolymer represents one of the most effective environmental friendly alternatives to the conventional Portland cement binders. Reducing the need for cement, thus saving energy, bringing this waste by-product to the market, will help to reduce industrial and air pollution. In this study, the mechanical properties of geopolymer samples produced by using different amounts of fly ash and metakaolin were investigated with sodium and magnesium sulfate effects. 7 and 28 days compressive and flexural strength and ultrasonic pulse velocity results were investigated for 4 series samples with together unit weight, water absorption and porosity results. The highest yielding series sample was exposed to $10 \%$ magnesium and sodium sulfate solutions for up to 56 days. Geopolymer mortars were placed in an oven at $105^{\circ} \mathrm{C}$ for 24 hours to improve absorption of sulfate ions before being exposed to the solutions. The results of weight change, ultrasonic pulse velocity, compressive and flexural strength after 14, 28 and 56 days immersion in each sulfate solution were compared.
\end{abstract}

Keywords: Cement, geopolymer, Portland cement, compressive strength, flexural strength

\footnotetext{
* Corresponding Author:

E-mail: aygormez@yildiz.edu.tr (Y. Aygörmez)
} 


\section{INTRODUCTION}

Under the influence of sulfate solution, in concrete or cement systems, sulfate ions enter the cement matrix and react with cement hydration products and cause expansion, spalling and cracks [Neville, 2004], [Nie, 2015]. Specifically, ettringite, gypsum, thaumasite and monosulfate are formed as a result of this reaction and these products lead to expansion, cracking, loss of strength and serious deterioration of concrete and cement [Hossack and Thomas, 2015]. In order to solve the problems relating to Portland cement, the researchers tend to produce a cement-free binder.

Geopolymer was first developed by Davidovits and produced from an aluminosilicate source such as fly ash, slag, metakaolin. In a high alkaline environment, the binders are then mixed with alkali silicate solution [Davidovits, 1991]. Geopolymer is favoured for early compressive strength, good resistance to chemical effects, high temperature resistance and low permeability. Geopolymer is a sustainable building material that is an alternative to traditional Portland cement in the presence of sulfates.

Although it is possible to use different binders in the production of geopolymer samples, the most advantageous binding material in this regard is the fly ash produced in thermal plants [Duan et al., 2015]. When metakaolin with high pozzolanic properties and fine particles is used as binder material, early setting time occurs and a high compressive strength can achieved [Kannan and Ganesan, 2014]. Therefore, recently metakaolin has been widely used in geopolymer systems.

Metakaolin, which is used as the main binding material for the production of geopolymer, is produced de-hydroxylation of kaolin [Duxson et al., 2007]. The basic components of metakaolin are $\mathrm{Al}_{2} \mathrm{O}_{3}$ and $\mathrm{SiO}_{2}$ and it is widely used in geopolymer production due to their mechanical, porosity and durability properties [Cheng et al., 2012]. The performance of metakaolin-based geopolymer depends on the type of metakaolin, the amount and concentration of activator, and the curing system [Roviello et al., 2015]. Researchers have studied the mechanical and durability properties. The metakaolin used in the geopolymer production is also used as a substitute in cement based products [Zhou et al., 2016].

Fly ash is used for geopolymerization as a source of aluminosilicate because it is rich in $\mathrm{SiO}_{2}$ and $\mathrm{Al}_{2} \mathrm{O}_{3}$ which are essential oxides for geopolymer [Nguyen et al, 2016]. Fly ash has been studied in many geopolymer surveys as pozzolanic materials because of the worldwide widespread waste material [Nath et al, 2016].

Numerous studies have been published on the durability of geopolymer composites. Researchers agree that geopolymer has high early compressive strengths, excellent fire resistance and low permeability. Recently, through to their ceramic-like microstructure, geopolymer composites offer a promising solution to sulfate attack. There are limited studies on sulfate effect in geopolymer samples when fly ash and metakaolin are used as binding materials. In this study, the mechanical properties of geopolymer samples produced by using different amounts of fly ash and metakaolin were investigated with sodium and magnesium sulfate effects. 7 and 28 days compressive and flexural strength and ultrasonic pulse velocity results were investigated for 4 series samples with together unit weight, water absorption and porosity results. The highest yielding series sample was exposed to $10 \%$ magnesium and sodium sulfate solutions for up to 56 days. Geopolymer 
mortars were placed in an oven at $105^{\circ} \mathrm{C}$ for 24 hours to improve absorption of sulfate ions before being exposed to the solutions. The results of weight change, ultrasonic pulse velocity, compressive and flexural strength after 14, 28 and 56 days immersion in each sulfate solution were compared.

\section{MATERIALS AND METHODS}

\section{Materials}

Fly ash, metakaolin and slag. In this study, metakaolin, fly ash (F class) and slag, were provided from Kaolin EAD (Turkey, Istanbul), Cates electrical production Inc., Catalagzi/Zonguldak and Bolu Cement Company (Bolu /Turkey), respectively. The specific gravity of slag, metakaolin and fly ash was $2.91 \mathrm{~g} / \mathrm{cm}^{3}, 2.52 \mathrm{~g} / \mathrm{cm}^{3}$ and $1.96 \mathrm{~g} / \mathrm{cm}^{3}$, respectively. The chemical components of the binder materials are given in Table 1.

Table 1. Chemical composition of fly ash, metakaolin, and slag (wt\%)

\begin{tabular}{|c|c|c|c|c|c|c|c|c|c|}
\hline & $\mathrm{SiO}_{2}$ & $\mathrm{Al}_{2} \mathrm{O}_{3}$ & $\mathrm{Fe}_{2} \mathrm{O}_{3}$ & $\mathrm{TiO}_{2}$ & $\mathrm{CaO}$ & $\mathrm{MgO}$ & $\mathrm{K}_{2} \mathrm{O}$ & $\mathrm{Na}_{2} \mathrm{O}$ & L.O.I. \\
\hline Fly ash & 54.08 & 26.08 & 6.68 & - & 2.00 & 2.68 & 4.54 & 0.79 & 1.36 \\
\hline Metakaolin & 56.10 & 40.23 & 0.85 & 0.55 & 0.19 & 0.16 & 0.51 & 0.24 & 1.10 \\
\hline Slag & 40.55 & 12.83 & 1.10 & 0.75 & 35.58 & 5.87 & 0.68 & 0.79 & 0.03 \\
\hline
\end{tabular}

Activator. The sodium hydroxide solution was prepared one day before the mixture and mixed with sodium silicate on the same day of the experiment. Sodium hydroxide and sodium silicate solutions were used as alkali activators. They were provided from Merck. The molar ratio of the sodium silicate solution was $3.29\left(\mathrm{Na}_{2} \mathrm{O}=8.2 \%, \mathrm{SiO}_{2}=27 \%\right)$. Sodium hydroxide solution was prepared as $12 \mathrm{M}$.

Aggregate. A standard sand according to BS EN 196-1 was added.

\section{Experimental Study}

Table 2 shows the amounts of materials for geopolymer mortars. Geopolymer mortars were produced with fly ash and metakaolin. The binding material was first mixed with the activator prepared the day before mixing. The binding material/activator ratio was determined as 1:0.6. Then, as a calcium source, a blast furnace slag was added to the mixture. The standard sand was added to the geopolymer paste as an aggregate, and the ratio of aggregate/binding material was 2.5:1. The mortar mixture was subjected to vibration after being placed in the molds. Curing was done in an oven at $80{ }^{\circ} \mathrm{C}$ for 24 hours. 
Table 2. Geopolymer mortar mixing proportions (g)

\begin{tabular}{|c|c|c|c|c|c|c|}
\hline & Fly Ash & Metakaolin & Standard sand & $\mathrm{NaOH}(12 \mathrm{M})$ & $\mathrm{Na}_{2} \mathrm{SiO}_{3}$ & Slag \\
\hline Series 1 & 450 & 0 & 1125 & 90 & 180 & 60 \\
\hline Series 2 & 427.5 & 22.5 & 1125 & 90 & 180 & 60 \\
\hline Series 3 & 405 & 45 & 1125 & 90 & 180 & 60 \\
\hline Series 4 & 382.5 & 67.5 & 1125 & 90 & 180 & 60 \\
\hline
\end{tabular}

The compressive and flexural strength and ultrasonic pulse velocity results of geopolymer mortars determined at 7 and 28 days were compared. Magnesium and sodium sulfate were used as a solution. Geopolymer mortars were immersed in solutions of $10 \%$ sodium sulfate or $10 \%$ magnesium sulfate for up to 56 days and the results of weight change, compressive and flexural strength, ultrasonic pulse velocity after 14, 28 and 56 days were compared. Before immersion in each sulfate solution, geopolymer mortars were placed at $105^{\circ} \mathrm{C}$ for 24 hours to better absorb the sulfate solutions.

\section{EXPERIMENTAL RESULTS}

When water absorption, porosity and unit weight results were examined, it was observed that water absorption and porosity values decreased and unit weight values increased because of the more intensive structure with the contribution of metakaolin (Table 3). The results of compressive and flexural strength and ultrasonic pulse velocity of geopolymer mortar samples at 7 and 28 days are given in Table 4 . When the results were examined, it was observed that there was an increase in all of the mixtures in 28 days according to 7 days. The increase rates in the compressive strength results were between $2.92 \%$ and $3.28 \%$, while the increase in flexural strength results were between $6.50 \%$ and $12.58 \%$. On the other hand, the rates of increase in ultrasonic pulse velocity were between $1.05 \%$ and $1.36 \%$. The highest results were obtained in $15 \%$ metakaolin $+85 \%$ fly ash mixture results. Because a denser structure of geopolymer specimens containing metakaolin can be found. However, using metakaolin at a higher rate is not sustainable due to its cost. Results found are compatible with those from other studies [Duan et al, 2015].

Table 3. Physical properties of geopolymer mortars

\begin{tabular}{|c|c|c|c|}
\hline & $\begin{array}{c}\text { Water absorption } \\
(\boldsymbol{\%})\end{array}$ & Unit weight $\left(\mathbf{g} / \mathbf{c m}^{\mathbf{3}}\right)$ & Porosity (\%) \\
\hline Series 1 & 7.72 & 2.38 & 14.51 \\
\hline Series 2 & 7.56 & 2.40 & 14.13 \\
\hline Series 3 & 7.34 & 2.43 & 13.89 \\
\hline Series 4 & 6.85 & 2.45 & 13.67 \\
\hline
\end{tabular}


Table 4. Compressive and flexural strength and ultrasonic pulse velocity results of geopolymer mortars at various days of curing

\begin{tabular}{|c|c|c|}
\hline & $\begin{array}{l}\text { Compressive strength } \\
\text { (MPa) } 7 \text { Days }\end{array}$ & $\begin{array}{l}\text { Compressive strength } \\
\text { (MPa) } 28 \text { Days }\end{array}$ \\
\hline Series 1 & 49.68 & 51.31 \\
\hline Series 2 & 50.75 & 52.23 \\
\hline Series 3 & 55.84 & 57.62 \\
\hline \multirow[t]{2}{*}{ Series 4} & 57.45 & 59.25 \\
\hline & $\begin{array}{c}\text { Flexural strength }(\mathrm{MPa}) \\
7 \text { Days }\end{array}$ & $\begin{array}{c}\text { Flexural strength }(\mathrm{MPa}) \\
28 \text { Days }\end{array}$ \\
\hline Series 1 & 8.05 & 8.78 \\
\hline Series 2 & 8.27 & 9.31 \\
\hline Series 3 & 9.18 & 9.89 \\
\hline \multirow[t]{2}{*}{ Series 4} & 9.54 & 10.16 \\
\hline & $\begin{array}{c}\text { Ultrasonic pulse } \\
\text { velocity }(\mathrm{m} / \mathrm{s}) 7 \text { Days }\end{array}$ & $\begin{array}{c}\text { Ultrasonic pulse } \\
\text { velocity }(\mathrm{m} / \mathrm{s}) 7 \text { Days }\end{array}$ \\
\hline Series 1 & 3494 & 3532 \\
\hline Series 2 & 3518 & 3555 \\
\hline Series 3 & 3539 & 3587 \\
\hline Series 4 & 3564 & 3612 \\
\hline
\end{tabular}

The mixture consisted of $15 \%$ metakaolin $+85 \%$ fly ash was exposed to magnesium and sodium sulfate solutions at the end of 28 days. The results are given in Figure 1-4. Samples were removed from the solutions after 14, 28 and, 56 days and allowed to dry at room temperature. Then the surfaces were cleaned with a wire brush and weight, strength and ultrasonic pulse velocity changes were evaluated.

Figures 1 and 3 show that the results of compressive strength and ultrasonic pulse velocity continued to increase up to 28 days. The increase in compressive strength ranged from $3.41 \%$ to $7.43 \%$ in the $10 \% \mathrm{MgSO}_{4}$ solution up to 28 days, while the increase in compressive strength ranged from $4.95 \%$ to $10.92 \%$ in the $10 \% \mathrm{Na}_{2} \mathrm{SO}_{4}$ solution up to 28 days. After 28 days, the strength results decreased in 56 days, although the increase continued according to the situation that was not exposed to the solution. The increase was $6.21 \%$ in 56 days compared to unexposed sample for $10 \% \mathrm{MgSO}_{4}$ solution, whereas the increase was $8.25 \%$ in 56 days compared to unexposed sample for $10 \% \mathrm{Na}_{2} \mathrm{SO}_{4}$ solution. 
The increase in ultrasonic pulse velocity ranged from $0.14 \%$ to $0.91 \%$ in the $10 \% \mathrm{MgSO}_{4}$ solution up to 28 days, while the increase in ultrasonic pulse velocity ranged from $1.16 \%$ to $2.13 \%$ in the $10 \% \mathrm{Na}_{2} \mathrm{SO}_{4}$ solution up to 28 days. After 28 days, the ultrasonic pulse velocity results decreased in 56 days, although the increase continued according to the situation that was not exposed to the solution. The increase in ultrasonic pulse velocity was $0.72 \%$ in 56 days compared to unexposed sample for $10 \% \mathrm{MgSO}_{4}$ solution, whereas the increase in ultrasonic pulse velocity was $1.55 \%$ in 56 days compared to unexposed sample for $10 \% \mathrm{Na}_{2} \mathrm{SO}_{4}$ solution.

The transitions between the solutions and the sample played an important role in the results of compressive strength and ultrasonic pulse velocity. Alkaline ions migrated from the sample to the solution and magnesium and sodium ions migrated from the solution to the sample and this situation played a role in the continuation of geopolymerization. According to the sulfate effect, fluctuations in compressive strength and ultrasonic pulse velocity results were observed up to 56 days. These fluctuations were due to the diffusion of $\mathrm{Mg}$ and $\mathrm{Na}$ to the matrix during the transition of alkali ions from the samples to the solution. As already reported, the samples were placed in an oven at $105{ }^{\circ} \mathrm{C}$ for 24 hours before the immersion test. Due to the this situation, weight increase occurred (Figure 4). The flexural strength (Figure 2) decreased as it reacted with the solution. The decreasing rates of flexural strength in the $10 \% \mathrm{MgSO}_{4}$ solution ranged from $4.72 \%$ to $18.80 \%$, while the reduction in flexural strength in the $10 \% \mathrm{Na}_{2} \mathrm{SO}_{4}$ solution ranged from $2.66 \%$ to $14.86 \%$. After exposure to magnesium and sodium sulfate solutions for up to 56 days, in case of visual inspection of samples, no damage was observed. This shows that geopolymer samples are highly resistant to sulfate solution. Magnesium sulfate is more effective and stronger than sodium sulfate, so the results improved for the samples immersed in the in sodium sulfate solutions. The results are consistent with the previous results [Duan et al, 2015], [Elyamany et al, 2018].

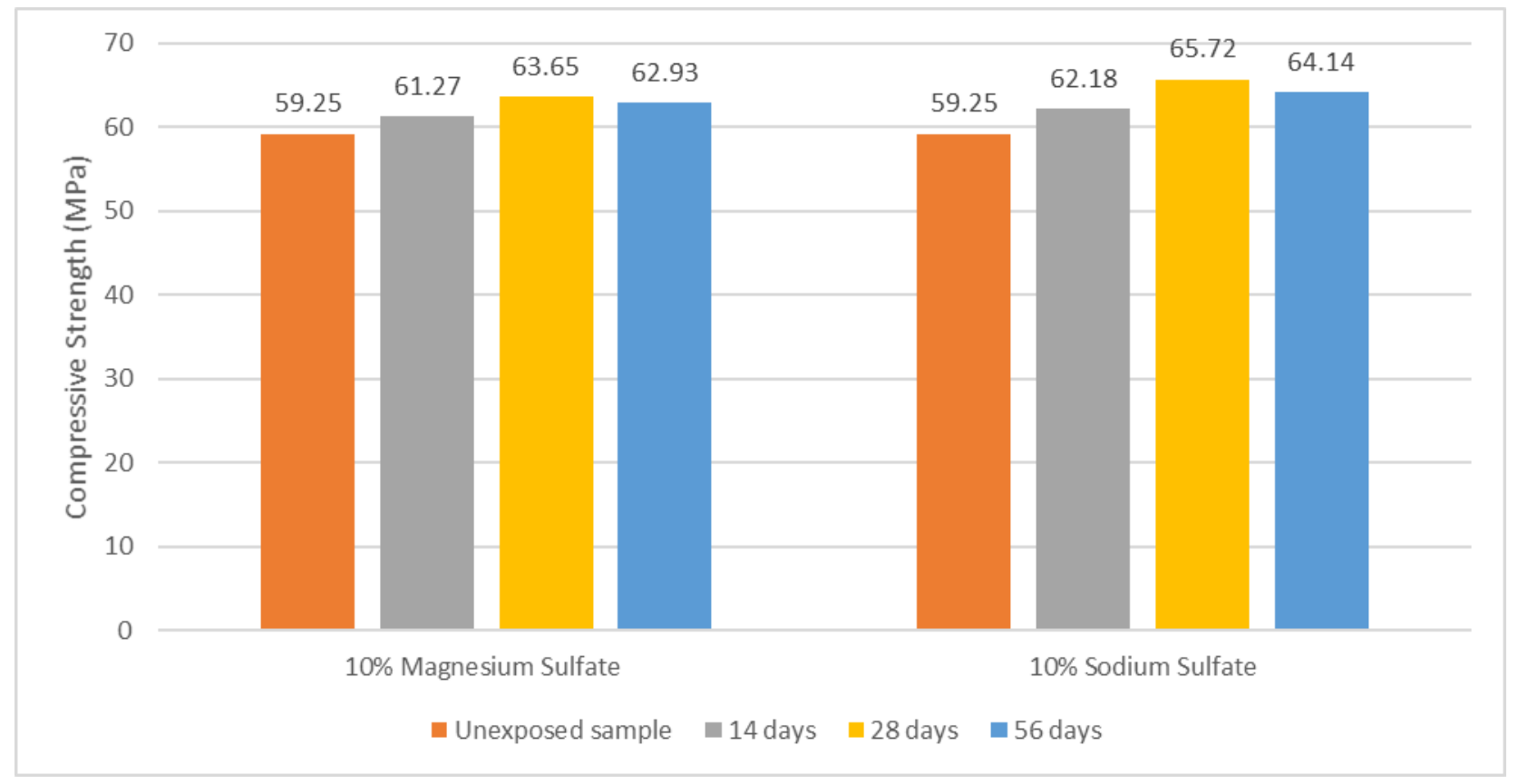

Figure 1. Compressive strength test results 


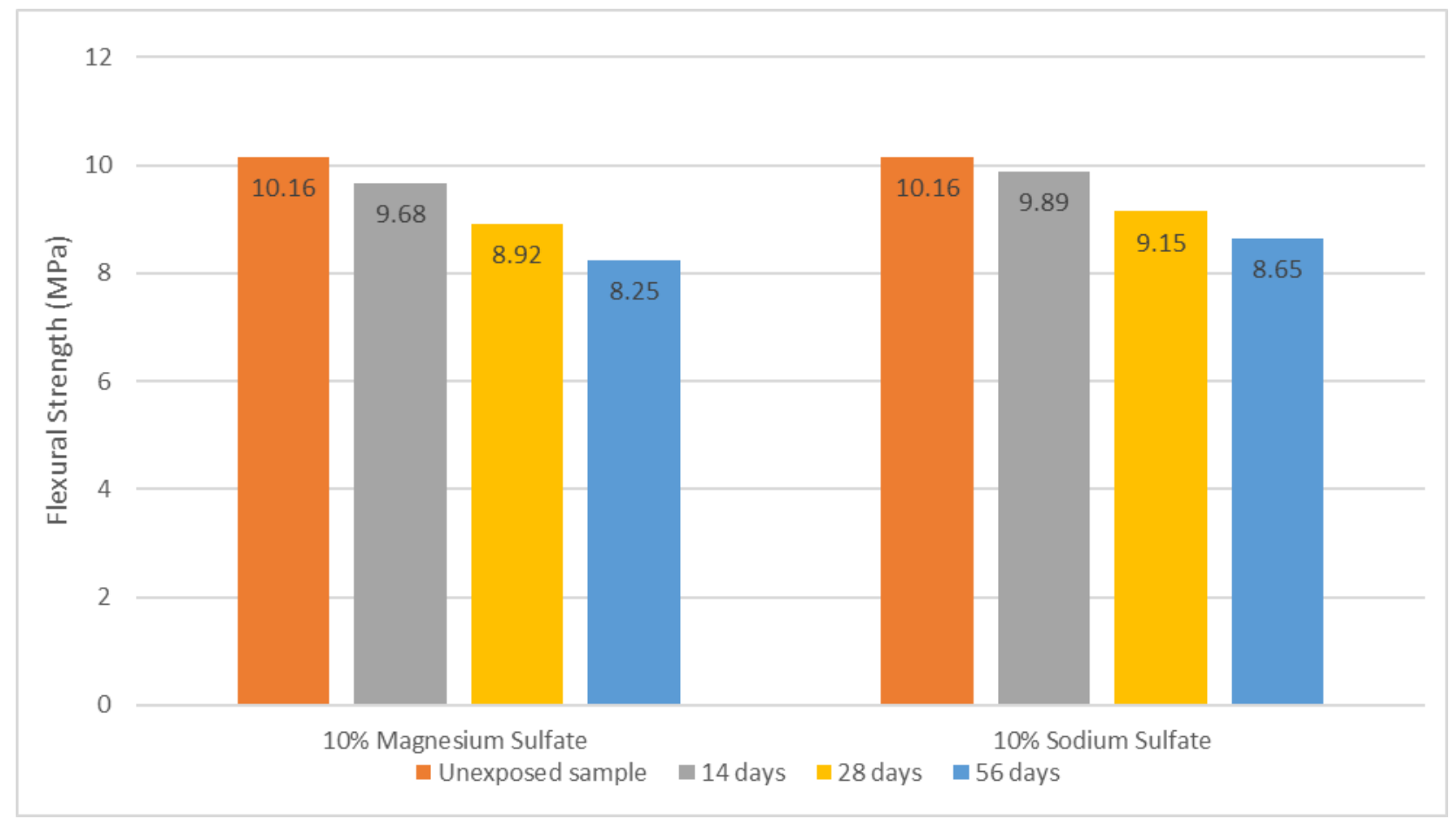

Figure 2. Flexural strength test results

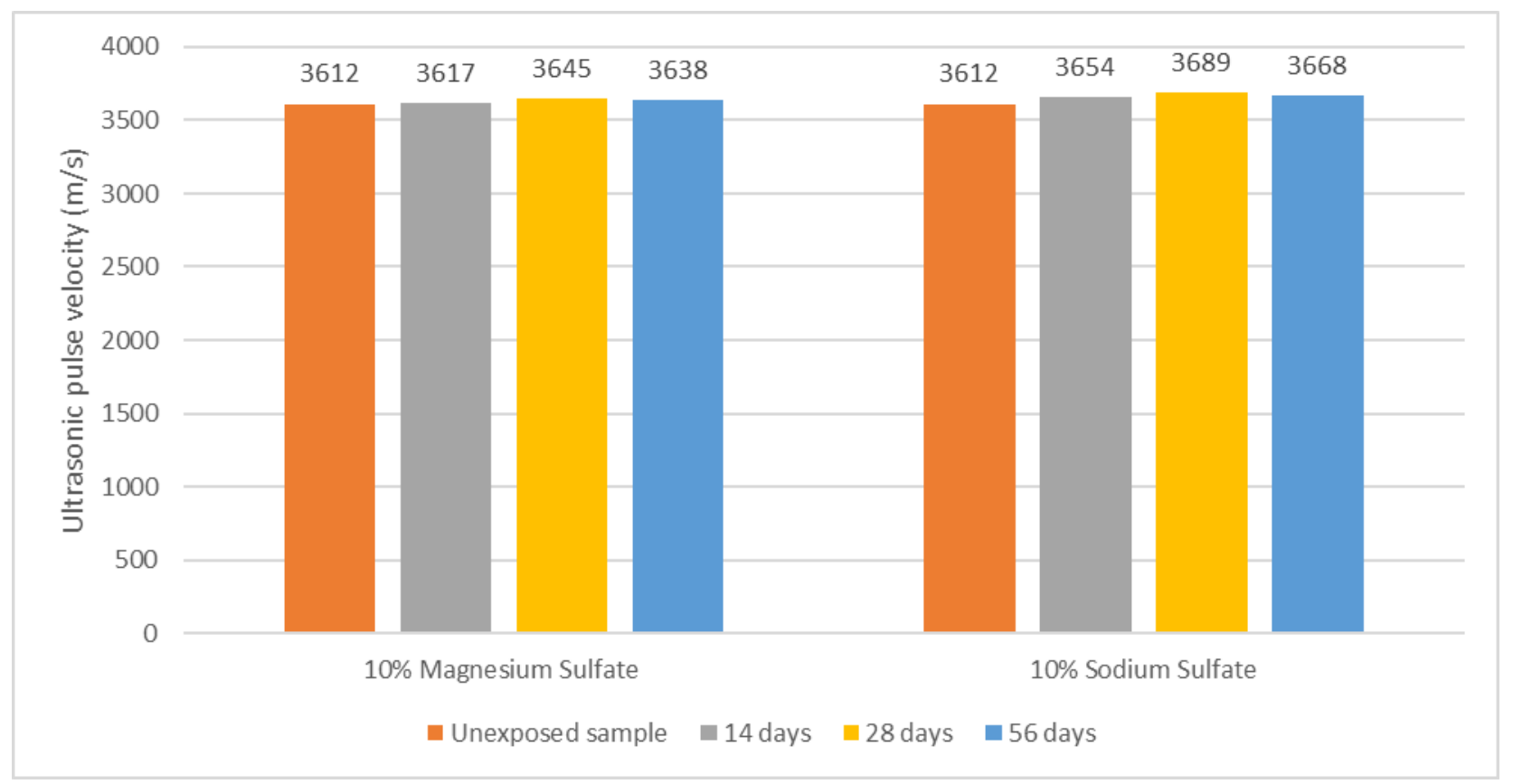

Figure 3. Ultrasonic pulse velocity test results 


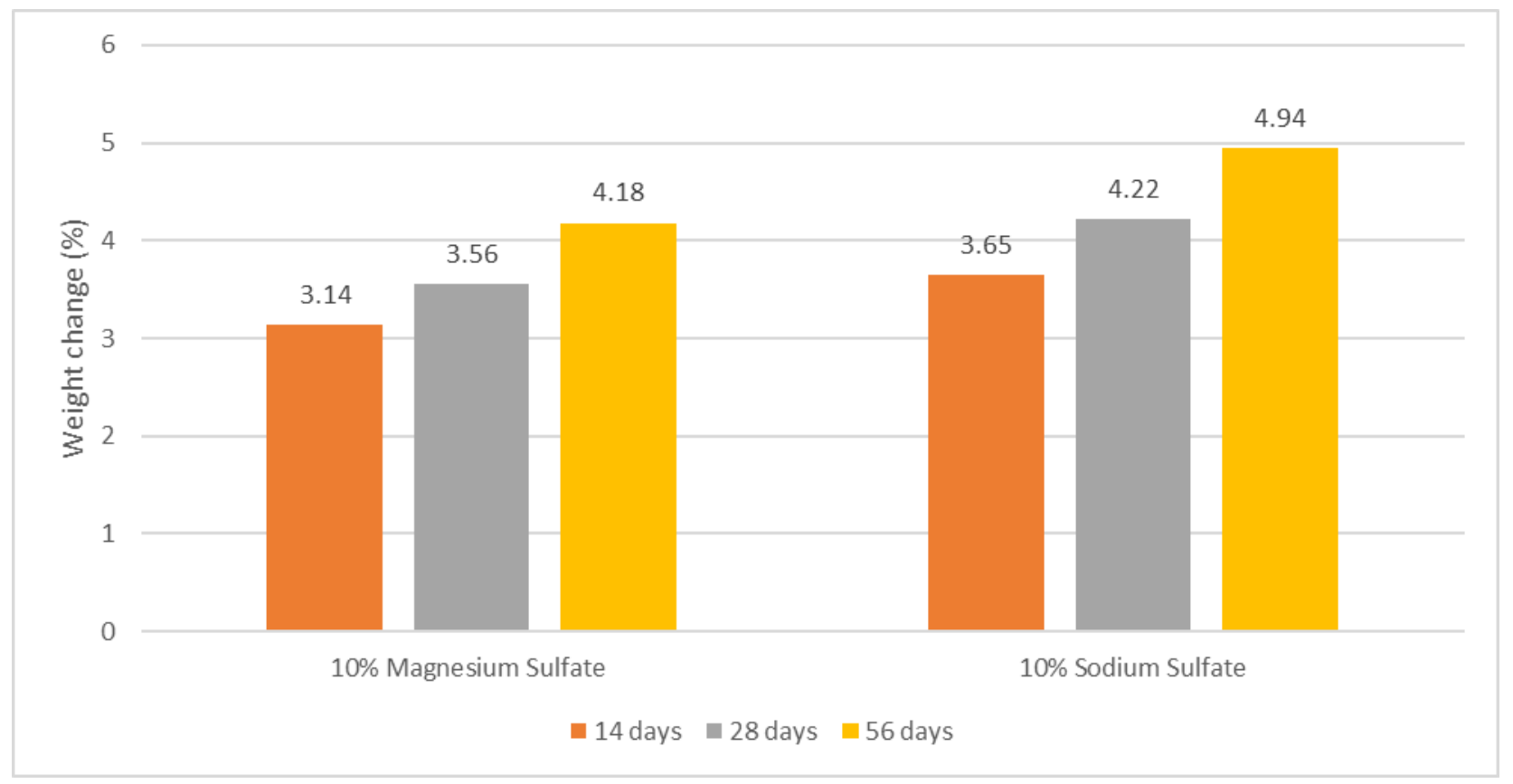

Figure 4. Weight change test results

\section{CONCLUSIONS AND RECOMMENDATIONS}

The results of the experimental study are listed below:

- The highest results were obtained in $15 \%$ metakaolin $+85 \%$ fly ash mixture results. Because a denser structure of geopolymer specimens containing metakaolin can be found. However, using metakaolin at a higher rate is not sustainable due to its cost. The geopolymer mortar sample obtained using $85 \%$ fly ash $+15 \%$ metakaolin exhibited a good performance when exposed to $10 \%$ sodium sulfate and $10 \%$ magnesium sulfate solution. Geopolymer samples are produced using waste material, fly ash, which is an important parameter in terms of sustainability and environmental protection.

- The increase in compressive strength ranged from $3.41 \%$ to $7.43 \%$ in the $10 \% \mathrm{MgSO}_{4}$ solution up to 28 days, while the increase in compressive strength ranged from $4.95 \%$ to $10.92 \%$ in the $10 \% \mathrm{Na}_{2} \mathrm{SO}_{4}$ solution up to 28 days. The increase was $6.21 \%$ in 56 days compared to unexposed sample for $10 \% \mathrm{MgSO}_{4}$ solution, whereas the increase was $8.25 \%$ in 56 days compared to unexposed sample for $10 \% \mathrm{Na}_{2} \mathrm{SO}_{4}$ solution. The increase in ultrasonic pulse velocity ranged from $0.14 \%$ to $0.91 \%$ in the $10 \% \mathrm{MgSO}_{4}$ solution up to 28 days, while the increase in ultrasonic pulse velocity ranged from $1.16 \%$ to $2.13 \%$ in the $10 \% \mathrm{Na}_{2} \mathrm{SO}_{4}$ solution up to 28 days. The increase in ultrasonic pulse velocity was $0.72 \%$ in 56 days compared to unexposed sample for $10 \% \mathrm{MgSO}_{4}$ solution, whereas the increase in ultrasonic pulse velocity was $1.55 \%$ in 56 days compared to unexposed sample for $10 \% \mathrm{Na}_{2} \mathrm{SO}_{4}$ solution. The transitions between the solutions and the sample played an important role in the results of compressive strength and ultrasonic pulse velocity. Magnesium sulfate is more effective and stronger than sodium sulfate, so the results were higher in sodium sulfate solutions. 
- The flexural strength decreased as it reacted with the solution. The decreasing rates of flexural strength in the $10 \% \mathrm{MgSO}_{4}$ solution ranged from $4.72 \%$ to $18.80 \%$, while the reduction in flexural strength in the $10 \% \mathrm{Na}_{2} \mathrm{SO}_{4}$ solution ranged from $2.66 \%$ to $14.86 \%$.

- The samples were placed in an oven at $105^{\circ} \mathrm{C}$ for 24 hours before the immersion test. Due to the this situation, weight increase occurred.

- Since geopolymer is a product resistant to sulfate solution, the duration of exposure should be increased even further for 56 days. It is useful to understand the behavior of the geopolymer matrix under sulfate solution.

\section{ACKNOWLEDGEMENT}

This work was supported by research fund of the Yildiz Technical University, the authors would like to express their sincere gratitude to scientific research coordination unit for their financial support to the project (Project number: 2016-05-01-DOP04).

\section{REFERENCES}

Neville A. (2004). "The confused world of sulfate attack on concrete." Cem. Concr. Res. 34(8), 1275-1296.

Nie Q.K., Zhou C.J., Li H.W., Shu X., Gong H.R. and Huang B.S. (2015). "Numerical simulation of fly ash concrete under sulfate attack." Constr. Build. Mater. 84, 261-268.

Hossack A.M. and Thomas M.D.A. (2015). "The effect of temperature on the rate of sulfate attack of Portland cement blended mortars in Na2SO4 solution.” Cem. Concr. Res. 73, 136-142.

Davidovits J. (1991). "Geopolymers: inorganic polymeric new materials." J. Therm. Anal. Calorim. 37, 1633-1656.

Duan P., Yan C.J., Zhou W., Luo W.J. and Shen C.H. (2015). "An investigation of the microstructure and durability of a fluidized bed fly ash-metakaolin geopolymer after heat and acid exposure." Mater. Des. 74, 125-137.

Kannan V. and Ganesan K. (2014). "Chloride and chemical resistance of self-compacting concrete containing rice husk ash and metakaolin.” Constr. Build. Mater. 51, 225-234.

Duxson P., Lukey G.C. and Van Deventer J.S.J. (2007). "Physical evolution of Na-geopolymer derived from metakaolin up to 1000 degrees." J. Mater. Sci. 42, 3044-3054.

Cheng T.W., Lee M.L., Ko M.S., Ueng T.H. and Yang S.F. (2012). "The heavy metal adsorption characteristics on metakaolin-based geopolymer." Appl. Clay Sci. 56, 90-96.

Roviello G., Menna C., Tarallo O., Ricciotti L., Ferone C., Colangelo F., Asprone D., Maggio R., Cappelletto E. and Prota A. (2015). "Preparation, structure and properties of hybrid materials based on geopolymers and polysiloxanes." Materials and Design 87, 82-94. 
Zhou W., Yan C., Duan P., Liu Y., Zhang Z., Qiu X. and Li D. (2016). “A comparative study of high-and low- $\mathrm{Al}_{2} \mathrm{O}_{3}$ fly ash based-geopolymers: The role of mix proportion factors and curing temperature." Materials and Design 95, 63-74.

Nguyen K.T., Ahn N., Le T.A. and Lee K. (2016). “Theoretical and experimental study on mechanical properties and flexural strength of fly ash-geopolymer concrete." Constr. Build. Mater. 106, 65-77.

Nath S.K., Maitra S., Mukherjee S. and Kumar S. (2016). "Microstructural and morphological evolution of fly ash based geopolymers.” Constr. Build. Mater. 111, 758-765.

Duan P., Yan C. and Zhou W. (2015). "Influence of partial replacement of fly ash by metakaolin on mechanical properties and microstructure of fly ash geopolymer paste exposed to sulfate attack." Ceramics International 42, 3504-3517.

Elyamany H.E., Elmoaty A.E.M.A. and Elshaboury A.M. (2018). "Magnesium sulfate resistance of geopolymer mortar." Construction and Building Materials 184, 111-127. 